\title{
A mercantilização da educação superior brasileira e as estratégias de mercado das instituições lucrativas
}

CRISTINA HELENA ALMEIDA DE CARVALHO

Universidade de Brasília

\section{INTRODUÇÃO}

O presente artigo tem como objetivo mapear o fenômeno recente de mercantilização da educação superior brasileira, dado pelo crescimento das Instituições de Educação Superior (IES) lucrativas e a adoção de diversas estratégias de mercado na direção da financeirização, oligopolização e internacionalização.

O predomínio das instituições privadas no Brasil teve início com a Reforma Universitária de 1968 implementada durante o regime militar, que incentivou o surgimento e a manutenção, a princípio, de estabelecimentos isolados. Até então, o segmento privado compunha-se de um conjunto de IES confessionais e comunitárias; e, como não se previa juridicamente a existência de empresas educacionais, todas foram denominadas como instituições sem fins lucrativos e, portanto, beneficiadas pela renúncia fiscal dos impostos sobre a renda, o patrimônio e os serviços, bem como pelo acesso a recursos federais.

Antes disso, na Constituição Federal de 1934, os estabelecimentos educacionais primários e profissionais ficaram isentos do pagamento de quaisquer tributos. A partir da Constituição Federal de 1946, a figura jurídica da imunidade substituiu a isenção e foi ampliada a todas as instituições de educação. Na redação mais atual que consta da Carta Magna de 1988, destaca-se o 
Art. 150. Sem prejuízo de outras garantias asseguradas ao contribuinte, é vedado à União, aos Estados, ao Distrito Federal e aos Municípios: [...]

VI - instituir impostos sobre: [...]

c) patrimônio, renda ou serviços dos partidos políticos, inclusive suas fundações, das entidades sindicais dos trabalhadores, das instituições de educação e de assistência social, sem fins lucrativos, atendidos os requisitos da lei.

O arcabouço legal ocultou o avanço no crescimento de grandes estabelecimentos mercantis que foram sendo aglutinados e transformados em universidades sem fins lucrativos. Tal situação perdurou até a promulgação da Lei de Diretrizes e Bases da Educação Nacional (LDB), em 1996, quando passou a existir o modelo institucional de estabelecimentos educacionais lucrativos. Conforme consta do texto da LDB (Brasil, 1996):

Art.20. As instituições privadas de ensino se enquadrarão nas seguintes categorias: I - particulares em sentido estrito, assim entendidas as que são instituídas e mantidas por uma ou mais pessoas físicas ou jurídicas de direito privado que não apresentem as características dos incisos abaixo;

II - comunitárias, assim entendidas as que são instituídas por grupos de pessoas físicas ou por uma ou mais pessoas jurídicas, inclusive cooperativas educacionais, sem fins lucrativos, que incluam na sua entidade mantenedora representantes da comunidade; (Redação dada pela Lei no 12.020 , de 2009)

III - confessionais, assim entendidas as que são instituídas por grupos de pessoas físicas ou por uma ou mais pessoas jurídicas que atendem a orientação confessional e ideologia específicas e ao disposto no inciso anterior;

IV - filantrópicas, na forma da lei.

O artigo foi regulamentado pelo decreto n. 2.207/1997, posteriormente substituído pelo decreto n. 2.306/1997, no governo Fernando Henrique Cardoso. Esse aparato normativo estabeleceu uma série de requisitos necessários para diferenciação entre as instituições não lucrativas e as empresas educacionais. Com isso, para aquelas que assumissem a configuração jurídica de instituições lucrativas, a vedação à cobrança de impostos sobre a renda, o patrimônio e os serviços cairiam por terra, assim como o acesso às verbas públicas.

A legislação explicitou a existência até então dissimulada de um processo de mercantilização da educação superior, já diagnosticado por João Silva Júnior e Valdemar Sguissardi (2000) ${ }^{1}$ e reafirmado por Sguissardi (2008) ${ }^{2}$ e Romualdo Oliveira

1 Para os autores, a mercantilização manifesta-se na educação superior brasileira, cuja "referência identitária para as instituições do setor privado é a empresa organizada de forma capitalista. Busca-se aproximação com o setor produtivo, não só por causa dos ingressos orçamentários, mas, também, como parâmetro para o que deve ser 'produzido' pelas IES” (Silva Júnior; Sguissardi, 2000, p. 171).

2 A mercantilização da educação superior é entendida por Sguissardi (2008) pela perspectiva teórica marxista, na qual a transformação em mercadoria é inerente à 
(2009), ora entendido como a transformação da educação em mercadoria, cujo preço é determinado pelo mercado com o intuito central de obter lucro em benefício de seus proprietários e acionistas, a despeito das limitações definidas pelo governo federal no que concerne aos reajustes das mensalidades e às sanções aos estudantes inadimplentes.

É importante salientar que embora a imunidade fiscal não fosse mais possível para as instituições lucrativas, a redução dos custos operacionais foi garantida para aquelas que aderiram ao Programa Universidade para Todos (PROUNI) a partir de 2005. Conforme já foi analisado nos trabalhos de Cristina Carvalho e Francisco Lopreato (2005) e de Carvalho (2006), a formulação do programa atendeu às demandas mais urgentes da iniciativa privada e este foi muito bem-vindo pelos estabelecimentos mercantis, na medida em que a adesão voluntária possibilitou a isenção do Imposto de Renda das Pessoas Jurídicas (IRPJ) e de três contribuições: Contribuição Social sobre o Lucro Líquido (CSLL), Contribuição Social para o Financiamento da Seguridade Social (COFINS) e Contribuição para o Programa de Integração Social (PIS).

A recuperação parcial da desoneração fiscal combinada ao novo status jurídico estimulou a expansão e a transformação de estabelecimentos não lucrativos em empresas educacionais, como se observa na Tabela 1 , cujas taxas anuais de crescimento, sobretudo de 1995 a 2002, de matrículas, instituições, concluintes em cursos presenciais foram muito superiores a seus congêneres sem fins lucrativos. Entre 2003-2008, a exceção ficou por conta do acréscimo semelhante em instituições nos dois modelos institucionais.

Tabela 1 - Taxas de crescimento anual nas IES particulares

\begin{tabular}{|c|c|c|c|c|c|c|c|c|}
\hline \multirow{2}{*}{$\begin{array}{l}\text { Dependência } \\
\text { Administrativa }\end{array}$} & \multicolumn{2}{|c|}{ Matrículas } & \multicolumn{2}{|c|}{ Cursos } & \multicolumn{2}{|c|}{ Instituições } & \multicolumn{2}{|c|}{ Concluintes } \\
\hline & $\begin{array}{l}1995- \\
-2002\end{array}$ & $\begin{array}{l}2003- \\
-2008\end{array}$ & $\begin{array}{l}1995- \\
-2002\end{array}$ & $\begin{array}{l}2003- \\
-2008\end{array}$ & $\begin{array}{l}1995- \\
-2002\end{array}$ & $\begin{array}{l}2003- \\
-2008\end{array}$ & $\begin{array}{l}1995- \\
-2002\end{array}$ & $\begin{array}{l}2003- \\
-2008\end{array}$ \\
\hline & $4,9 \%$ & $3,2 \%$ & $7,8 \%$ & $5,7 \%$ & $3,1 \%$ & $4,1 \%$ & $6,6 \%$ & $2,8 \%$ \\
\hline Privado total & $12,1 \%$ & $7,8 \%$ & $14,3 \%$ & $11,9 \%$ & $10,8 \%$ & $5,7 \%$ & $9,0 \%$ & $11,7 \%$ \\
\hline - Lucrativa* & $24,7 \%$ & $11,7 \%$ & $28,5 \%$ & $14,2 \%$ & $28,8 \%$ & $5,8 \%$ & $17,9 \%$ & $14,0 \%$ \\
\hline - Não lucrativa* & $9,6 \%$ & $2,6 \%$ & $10,3 \%$ & $8,4 \%$ & $-5,8 \%$ & $5,5 \%$ & $10,1 \%$ & $8,7 \%$ \\
\hline
\end{tabular}

Nota: *Os dados para IES lucrativas e não lucrativas só existem a partir de 1999.

Fonte: Carvalho (2011).

Elaboração da autora.

sociedade capitalista, e para a compreensão do fenômeno recorre a dois conceitos, ou duas faces da mesma moeda: a educação-mercadoria, como objeto de exploração de mais-valia ou de valorização pelos empresários da educação, mas até certo ponto também para os interesses privado/mercantis no aparelho do Estado; e a mercadoria-educação, dada pela expansão rápida de profissionais graduados (em algumas áreas específicas) que favorece o capital industrial, criando um exército de reserva que tende a rebaixar os salários dessa categoria profissional. Philip Altbach (2002) identifica a existência recente de transformação da educação em uma mercadoria (commodity) comprada e vendida no mercado. Em termos econômicos, commodity refere-se a um bem tradable, ou seja, comercializado internacionalmente, cujo preço é definido na bolsa de futuros nos Estados Unidos. 
Entre 2008 e 2009, houve ligeira queda nas matrículas presenciais privadas em virtude da redução drástica de estudantes em IES não lucrativas em torno de $36 \%$, enquanto as IES lucrativas tiveram acréscimo de $18 \%$ em um ano, o que demonstra que estas permanecem em franca expansão, embaladas pelo movimento de reorganização do mercado. Em 2009, o segmento lucrativo detinha 77\% das matrículas presenciais em estabelecimentos particulares. $\mathrm{O}$ movimento oposto é ainda mais visível nas matrículas em cursos a distância, com o aumento de $81 \%$ nas empresas educacionais e queda de $12 \%$ naquelas não lucrativas em um ano. Por sua vez, em 2009, o segmento lucrativo detinha 79\% das matrículas a distância em estabelecimentos particulares. Não foi possível verificar a trajetória dos dois modelos institucionais em 2010, uma vez que o Instituto Nacional de Estudos e Pesquisas Anísio Teixeira (INEP) divulgou os dados de forma agregada à classificação de privada, como fazia antes de 1999.

Ainda que a preservação da renúncia fiscal seja vantajosa, seu abandono por parte das IES é compensado pela possibilidade de recebimento de aporte adicional de capital, bem como por estas não estarem sujeitas ao maior rigor legal para comprovarem a condição de sem fins lucrativos. Ademais, há a questão patrimonial e sucessória em jogo, pois nesse modelo institucional o mantenedor não é dono do patrimônio construído pela instituição, nem pode deixá-lo aos seus sucessores.

A seguir, pretende-se analisar as diversas facetas do movimento recente de mercantilização no nível superior. A metodologia consiste na coleta de informações obtidas nos sites das IES lucrativas, bem como no relatório de fusões e aquisições publicado pela KPMG Corporate Finance e no divulgado pela CM Consultoria. Ademais, foram obtidas informações da Associação Brasileira de Private Equity e Venture Capital (ABVCAP) e da Bolsa de Valores de São Paulo (BM\&FBOVESPA).

\section{MERCANTILIZAÇÃO DA EDUCAÇÃO SUPERIOR E AS ESTRATÉGIAS DE MERCADO DAS EMPRESAS EDUCACIONAIS}

A tendência à mercantilização da educação superior não se restringe ao caso brasileiro. A transformação do setor educacional em objeto de interesse do grande capital é uma das consequências da globalização, especialmente nos países asiáticos e nos países desenvolvidos de origem anglo-saxônica, sobretudo nos Estados Unidos. ${ }^{3}$ Não é à toa que existem inúmeras pesquisas sobre o tema que se ocupam do caso americano, tais como: Kevin Kinser e Daniel Levy (2005), Ann Morey (2001), Kathleen Kelly (2001) e Yoni Ryan (2001). A despeito da divergência na classificação feita por esses atores sobre os modelos institucionais americanos de

3 Para uma análise das características, das dificuldades na definição e dos modelos institucionais que compreendem o setor mercantil americano, consultar: Kinser e Levy (2005). 
empresas educacionais, é possível identificar três tipos: as universidades corporativas, as universidades a distância e as universidades lucrativas. ${ }^{4}$

As universidades corporativas são bastante numerosas nos Estados Unidos. ${ }^{5}$ São instituições vinculadas a grandes corporações multinacionais, nas quais o aprendizado está associado ao desempenho, à capacidade de trabalhar de forma mais produtiva e criativa dentro do contexto da empresa ou, em níveis inferiores, simplesmente à competência para executar tarefas designadas como contabilidade ou trabalho manual. Essas instituições têm um perfil de treinamento, baseiam-se em procedimentos, no ciclo curto, são centradas em tarefas e, por isso, distanciam-se de um modelo tradicional universitário. No modelo de universidade a distância americano, existem inúmeros provedores privados; no entanto, somente a Jones International University oferece cursos exclusivamente on-line, concentrados em negócios e educação.

Por sua vez, as empresas educacionais americanas, bem como suas congêneres em outros países, diferenciam-se de forma significativa das instituições não lucrativas. De maneira bastante simplificada, a diferença reside na máxima: as primeiras fornecem educação para ganhar dinheiro, as segundas aceitam dinheiro para fornecer educação (Hawthorne apud Morey, 2001). Morey (2001, p. 307, tradução minha) é mais específica quando afirma que

Os valores fundamentais e princípios subjacentes a estes dois tipos de instituições são dessemelhantes, tais como: as decisões sobre o currículo, o tipo de corpo docente, funções da pesquisa e extensão, governança institucional, admissões, serviços e similares. De particular importância para esta discussão é a ênfase diferente na capacitação profissional e educação para a vida e para cidadania.

Nas instituições mercantis, a escolha programática é limitada e a maioria dos cursos é orientada para os negócios, sendo que essas evitam perspectivas teóricas que não sejam imediatamente aplicáveis e relevantes ao trabalho, da mesma forma que não há necessidade de pesquisa por parte dos professores, nem existe qualquer expectativa de serviço à comunidade. No entanto, esses modelos institucionais são bastante atraentes a uma clientela formada de alunos mais velhos, uma vez que ofertam cursos de curta duração, compostos por turmas pequenas e com parcas exigências (Ryan, 2001).

4 Para consulta da lista de universidades americanas que se enquadram no perfil em cada um dos modelos institucionais, ver Ryan (2001).

5 A pioneira americana foi a General Electric, que lançou a Crotonville Management Development Institute, em 1955, mas o interesse na criação de uma universidade corporativa, como complemento estratégico do gerenciamento do aprendizado e desenvolvimento dos funcionários de uma organização, ocorreu no final da década de 1980. Nos Estados Unidos, em 1988, quatrocentas empresas investiram em seus próprios centros de estudo e qualificação profissional; dez anos depois, já eram duas mil. 
Nos anos de 1990, as grandes instituições lucrativas passaram a ter suas ações negociadas na Associação Nacional Corretora de Valores e Cotações Automatizadas (NASDAQ) e na Bolsa de Valores de Nova York. Desde então, a educação superior tornou-se grande negócio e o segmento foi aquele que apresentou a maior taxa de crescimento de matrículas. A DeVry foi a primeira das grandes companhias educacionais a realizar oferta pública de ações em 1991, seguida pela Apollo Group, controladora da Universidade de Phoenix, cujas ações passaram a ser listadas na Bolsa de Valores de Nova York a partir de 1994. Essa teve um acréscimo brutal de alunos de dez mil, em 1990, para quase sessenta mil, no final de 1998. A cotação acionária do grupo Apollo começou em US\$2 por ação e em 2001 a negociação estava em cerca de US\$33 por ação (Morey, 2001).

No Brasil, o fenômeno de mercantilização acentua-se no final da década de 1990, no bojo do processo de globalização e de disseminação das tecnologias de informação, e manifesta-se, conforme salienta Romualdo Oliveira (2009), por meio da oferta direta de cursos (presenciais e a distância), da produção de materiais instrucionais (livros, apostilas e softwares), do surgimento de consultorias empresariais responsáveis tanto pela assessoria de empresas educacionais no mercado financeiro quanto na gestão de recursos ao setor.

A pioneira no ramo é a CM Consultores, que atua desde 1988, cujo proprietário é o professor Carlos Antônio Monteiro, especializada em gestão educacional, na oferta de cursos e seminários. Destacam-se ainda: a PRS Consultores, Lobo \& Associados Consultoria e a Hoper Educacional. A primeira era de propriedade do ex-ministro da educação Paulo Renato de Souza, que parece estar desativada. A segunda está em funcionamento desde 1999 e é de propriedade de Roberto Leal Lobo e Silva Filho, ex-reitor e vice-reitor da Universidade de São Paulo (USP) e ex-reitor da Universidade de Mogi das Cruzes, que oferece assessoria, consultoria, além de ministrar cursos, seminários, workshops, treinamentos aos gestores das IES privadas e vender uma série de "produtos" direcionados a atender sua clientela. Seus sócios fundaram, a partir de 2005, sob a denominação de Instituto Lobo para o Desenvolvimento da Educação, da Ciência e da Tecnologia, uma instituição sem fins lucrativos, com sede no mesmo local, com coincidência nas atividades, com exceção de oferta da assessoria e da consultoria. A terceira atua nas áreas de consultoria de gestão, estudos de mercado, educação executiva, produção de conteúdo e metodologias de ensino; foi fundada pelo professor Ryon Braga em 1997.

Por sua vez, os três modelos representantes do setor lucrativo existentes em solo americano tiveram seus congêneres nacionais. $O$ modelo de universidade corporativa teve origem em 1998, com a Universidade do Transporte proveniente da Transportadora Americana, seguida das empresas nacionais e multinacionais como Accor Brasil, Algar, Amil, AmBev, BankBoston, Elma Chips, Ford, McDonald's e Motorola. ${ }^{6} \mathrm{Na}$ sua maioria, essas instituições não têm campus, nem instalações

6 Há amplas diferenças entre universidades corporativas e instituições de ensino superior tradicionais. De acordo com Mauro Laruccia (2011, p. 147-148), "Enquanto a 
físicas definidas, uma vez que grande parte dos cursos ofertados é em formato virtual. Existem também outras experiências de empresas que, embora não se denominem de universidade corporativa, fazem uso de seus princípios conceituais e estão pautadas por uma abordagem de gestão do conhecimento e de competências, como por exemplo: Gessy Lever, Volkswagen/Audi, Datasul e Rhodia. É também tendência adotada pelos bancos públicos e privados para treinamento de seus funcionários/ servidores, como a Universidade Corporativa do Banco do Brasil e a Universidade Banco Central do Brasil (UniBacen). Vale salientar a inexistência de um levantamento oficial das empresas brasileiras que adotam o modelo de universidade corporativa, ${ }^{7}$ uma vez que o Ministério da Educação (MEC) não reconhece esse modelo institucional como pertencente ao sistema formal de nível superior brasileiro.

Já o modelo de universidade virtual particular opera no país sob a forma de consórcios de instituições, representado pela Rede Brasileira de Educação a Distância composta por seis instituições privadas $^{8}$ e a Rede de Instituições Católicas de Ensino Superior (RICESU). Ainda que as IES públicas e privadas venham adotando o formato não presencial em alguns de seus cursos, instituições exclusivamente virtuais são raras, até mesmo entre as IES particulares. ${ }^{9}$

As empresas educacionais passaram a adotar novas estratégias em face da concorrência acirrada promovida pelo recente surto expansivo nos anos de $1990 . \mathrm{Na}$ busca por "clientes", a diversificação de cursos possibilitou a oferta de modalidades de ensino com menor prestígio acadêmico, focadas na diferenciação em virtude da demanda ou do contexto local. São exemplos os cursos sequenciais, a distância e

universidade tradicional, que pertence ao sistema educacional formal, desenvolve competências para o mundo do trabalho propiciando aprendizagem baseada em formação conceitual sólida e universal, pela transmissão de crenças e valores universais da sociedade dentro e desenvolvendo a cultura acadêmica para formar cidadãos competentes para gerar o sucesso das instituições e da comunidade, a universidade corporativa, que pertence ao sistema de gestão da empresa, desenvolve competências para o mundo dos negócios; desenvolve aprendizagem baseada na prática dos negócios, pela transmissão de crenças e valores da empresa e de seu ambiente de negócios dentro e desenvolvendo a cultura empresarial para formar cidadãos competentes para gerar o sucesso da empresa e dos clientes.”.

7 De acordo com as estimativas da professora Marisa Eboli, que organiza um ranking entre as companhias nacionais, houve um crescimento extraordinário de $2.400 \%$ em dez anos, pois em 1999 eram 10 unidades, e em 2009 existiam 250 unidades (França, 2009).

8 A Rede Brasileira de Educação a Distância foi criada em 2000 e é o resultado da associação de seis instituições de ensino superior particular que formaram o Instituto Universidade Virtual Brasileira. São elas: Associação Educacional do Litoral Santista (Centro Universitário Monte Serrat) - SP; Associação Potiguar de Educação e Cultura (Universidade Potiguar) - RN; Instituto Cultural Newton Paiva Ferreira (Centro Universitário Newton Paiva) - MG; Instituto Superior de Comunicação Publicitária (Universidade Anhembi Morumbi) - SP; União Superior de Ensino do Pará (Universidade da Amazônia) - PA; e Universidade Veiga de Almeida - RJ.

9 A exceção, no caso brasileiro, é a Associação Internacional de Educação Continuada (AIEC), faculdade fundada em 1999 com o objetivo de ofertar cursos de administração a distância. 
de extensão e de pós-graduação lato sensu. Para algumas IES de pequeno porte, a solução foi permanecerem especializadas em um determinado nicho acadêmico, direcionadas ao extrato de maior renda, tais como a Escola Superior de Propaganda e Marketing (ESPM) e a Fundação Getúlio Vargas (FGV) e o Instituto Brasileiro de Mercado de Capitais (IBMEC).

Outras maneiras de conquistar a clientela incluem desde a adoção de estratégias de marketing agressivas direcionadas ao acesso imediato ao mercado de trabalho, mediante o uso da imagem de artistas e/ou modelos como exemplos de pessoas bem-sucedidas, até a divulgação de promoções nos valores das mensalidades, em clara competição predatória com o intuito de baratear para obter ganho em escala, sendo que o consumidor fica seduzido pelo preço a despeito da qualidade do serviço ofertado (Baldan, 2007). Ambas têm sido usadas como instrumentos para atrair a demanda; porém, não parecem ser suficientes para sustentar as IES fragilizadas pela concorrência, diante das elevadas taxas de inadimplência e de desistência. A primeira chega a 23\%; e a taxa de evasão a 25\%, sendo 27\% nas lucrativas (Holanda, 2007; Silva Filho et al., 2007).

Seguindo a tendência internacional, além das táticas adotadas pelas IES mercantis para envolver a clientela, foram promovidas transformações no âmbito dos negócios. Destaca-se, em primeiro lugar, a profissionalização da gestão dos estabelecimentos educacionais. Tendo em vista que a maior parte das mantenedoras é administrada por familiares, fez-se necessário o surgimento do "reitor profissional". Este seria um docente proveniente do segmento público, com a carreira acadêmica reconhecida, que atraído pelo salário elevado assumiria a "[...] mediação entre a Mantenedora e a mantida, administrando-a sob as diretrizes da política estratégica da mantenedora, cujo objetivo principal tenderá a ser o lucro financeiro e o aumento e estabilidade patrimoniais" (Silva Júnior; Sguissardi, 2000, p. 165). Um caso exemplar dessa tendência ocorreu na Universidade de Mogi das Cruzes, cujo reitor proveniente do quadro funcional da USP abriu, posteriormente, uma empresa de consultoria em educação, aqui já mencionada. Nessa linha, outra mudança organizacional importante consiste na adoção de modelos de excelência de gestão sugeridos pela Fundação Nacional da Qualidade (FNQ). Cabe exemplificar os estabelecimentos de ensino que adotaram o modelo, como: as Faculdades Rio Branco, a Universidade Bandeirantes de São Paulo (UNIBAN) e a Centro Universitário Hermínio Ometto (UNIARARAS) (Gorgulho, 2007).

A segunda estratégia reside na transfiguração de universidades e centros universitários em grandes conglomerados ou holdings. Isso vem ocorrendo por meio de reestruturação operacional, seja pela aquisição de instituições de porte médio ou pequeno em dificuldades financeiras, seja por meio de fusões de capital, cuja cooperação permite ganhos de escala e maior fatia de mercado, bem como novos nichos de mercado geográficos e vantagens pelo crescimento do número de alunos e de cursos já autorizados pelo MEC. O processo de concentração de capital toma novos ares com a abertura de capital de quatro empresas educacionais, como será abordado a seguir, já que estas se tornaram responsáveis pela maioria das operações de fusões e aquisições no setor. Casos exemplares são a compra do 
Centro Universitário Ibero-Americano (UNIBERO) pelo grupo Anhanguera Educacional, ${ }^{10} \mathrm{em} 2007$, seguida de perto pela Universidade Estácio de Sá, ${ }^{11}$ que adquiriu o Centro Universitário Radial (UNIRADIAL), em São Paulo, e a Kroton, de Belo Horizonte, que adquiriu, em 2011, o Centro de Ensino Atenas Maranhense. ${ }^{12}$ Por se tratarem de estabelecimentos de grande porte, essas operações são emblemáticas do movimento de oligopolização do setor, no formato de conglomerados educacionais, cuja mantenedora empresa holding controla os negócios das demais.

Novo indício do movimento de oligopolização pode ser constatado pela quantidade de fusões e aquisições. ${ }^{13}$ A KPMG Corporate Finance é uma rede global de empresas independentes que prestam serviços profissionais de audit, tax e advisory e é responsável pela publicação trimestral sobre a trajetória das fusões e aquisições na economia brasileira. No ano de 2007, houve 19 aquisições no setor educacional, o que motivou o desmembramento, a partir do ano seguinte, da classificação até então genérica de "outros" para o setor "educação". Em 2008, foram registradas 53 transações, o que levou o setor à impressionante posição de terceiro lugar no ranking nacional. Em 2009, em virtude da crise internacional que assolou o mercado financeiro em geral, e em especial o setor educacional, houve redução acentuada para 12 operações, ainda assim, o setor educacional ocupou a décima segunda posição entre os setores econômicos. Em 2010, ocorreu ligeira recuperação para 20 operações, mantendo-se o mesmo posicionamento, e em 2011 ocorreu novo aumento para 27 operações e a subida de uma posição no ranking de transações (KPMG, 2012).

Outra estratégia consiste na venda parcial do estabelecimento nacional ao capital estrangeiro. Como o projeto de reforma da educação superior se encontra no Congresso Nacional desde 2006, cujo teor limitaria a 30\% do capital total e votante das IES que poderia ser destinado a estrangeiros - inclusive com vedação de franquia -, não há até o momento nenhum óbice legal a esse tipo de movimento de internacionalização da oferta educacional. Seus precursores são: a Laureate Education, que adquiriu 51\% do capital da Universidade Anhembi Morumbi, em 2005, e 90\% do Centro Universitário Hermínio da Fonseca, em 2010; a Whitney

10 De acordo com informações de seu site, a empresa oferece cursos em sete estados, com mais de 140 mil alunos. Consultar a esse respeito: <http://www.unianhanguera.edu.br/ home/index.php>.

11 O site informa que em dezembro de 2011 eram 240 mil alunos nas modalidades presencial e a distância, nos cursos de graduação e pós-graduação, em 68 campi em 17 estados da federação. Consultar: <http://www.estacioparticipacoes.com/estacio2010/ web/conteudo_pt.asp?idioma $=0 \&$ conta $=28 \&$ tipo $=30092>$.

12 Conforme o site da empresa educacional, a Kroton conta com 38 campi, em 28 municípios, distribuídos em nove estados da federação. Consultar: <http://www. kroton.com.br/>.

13 Apesar de o relatório da KPMG não ter informação específica sobre a educação superior, quando os números são cotejados com aqueles da CM Consultoria, é possível perceber que a maioria das negociações é feita entre estabelecimentos de educação superior (CM, 2010). 
International University System, ${ }^{14}$ que adquiriu 60\% do capital das Faculdades Jorge Amado (Bahia), que em 2006 foi transformada em Centro Universitário Jorge Amado (UNIJORGE); e a rede DeVry University, que adquiriu 69\% da Faculdade Nordeste. As três representam grandes conglomerados provenientes de empresas americanas com ampla capilaridade no mundo dos negócios. Cabe destacar que a Apollo Internacional tentou realizar operação de compra da Universidade Paulista (UNIP) e do colégio Objetivo, em 2008, ambos de propriedade de João Carlos Di Gênio, cuja proposta envolvia $\mathrm{R} \$ 2,5$ bilhões, que foi prontamente recusada por seu proprietário. Esse grupo já havia adquirido parte do Grupo Pitágoras, em 2001, cujo negócio foi desfeito em 2006, quando o Grupo Pitágoras recomprou a parte do investidor internacional.

A manifestação mais significativa do fenômeno de mercantilização pode ser observada por meio das aquisições realizadas por fundos private equity e pela abertura de capital das empresas educacionais na bolsa de valores (IPOs) a partir de 2007. Os primeiros são fundos de investimento em participações de empresas de capital aberto ou fechado, com envolvimento posterior da entidade gestora/ investidora nos foros de gestão da entidade investida. ${ }^{15}$ Entre 2006 e o primeiro trimestre de 2010 foram realizadas cinco grandes operações. O banco Pátria realizou a aquisição por meio de um fundo de investimento em participações de 68\% da Anhanguera Educacional; a GP Investimentos adquiriu 20\% da Estácio Participações (2008); o Cartesian Capital Group comprou a Faculdade Maurício de Nassau (2008); o Advent adquiriu 50\% da Kroton Educacional (2009); Capital Intl efetuou a compra, no início de 2010, do IBMEC Educacional.

Os Fundos Private Equity têm condições de injetar somas elevadas de recursos nos negócios educacionais por intermédio de grupos fechados de grandes especuladores (nacionais e internacionais), mediante a exigência de reestruturação baseada na redução de custos, na racionalização administrativa, na profissionalização da gestão (Oliveira, 2009), e, sobretudo, na adoção dos princípios de "governança corporativa". O conceito surgiu nos Estados Unidos, na década de 1990, por um grupo de acionistas que pretendia criar novas regras para proteção contra os abusos das diretorias executivas e a inércia dos conselhos de administração das empresas. No Brasil, o primeiro código sobre o tema surgiu em 1999, elaborado pelo Instituto Brasileiro de Governança Corporativa (IBGC). Nele constavam quatro princípios fundamentais que devem ser observados pelas empresas: transparência, equidade, prestação de contas (accountability) e responsabilidade corporativa. Quanto aos "negócios" em educação superior, os princípios envolvem: perpetuar o negócio; melhorar a imagem institucional; garantir desempenho acima da média do mercado;

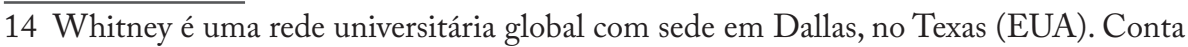
com instituições parceiras e escritórios nos Estados Unidos, por toda a América Latina, norte da África e Oriente Médio.

15 Consultar o site da Associação Brasileira de Private Equity e Venture Capital (ABVCAP): <http://www.abvcap.com.br>. 
facilitar a entrada de investimentos; reduzir os conflitos de interesses e os conflitos familiares; e garantir maior segurança quanto aos direitos dos proprietários. Este último aspecto torna-se central na medida em que o mercado considera que a instituição praticante da governança corporativa apresenta menor risco ao investidor. De acordo com Rodolfo Bonventti (2008), as três ferramentas que garantem uma gestão e governança de boa qualidade são: planejamento estratégico permanente e desafiador, por meio do qual a instituição se mobiliza para construir o seu futuro com base na intenção clara dos acionistas; gestão de risco capaz de identificar as vulnerabilidades, probabilidades de riscos e as oportunidades existentes no mercado e o desenvolvimento das pessoas, alinhando-as à estratégia de negócio da instituição.

Por fim, o movimento mais recente no mercado educacional brasileiro consiste na abertura de capital e na oferta pública de ações (IPOs) de empresas educacionais na BM\&FBOVESPA, em 2007, que foram classificadas no "nível 2" de governança corporativa, ou seja, enquadradas naquelas que têm obrigações adicionais relativas aos direitos dos acionistas e do conselho de administração. São elas: Universidade Anhanguera, Universidade Estácio de Sá, Faculdade Pitágoras e o Sistema COC de Educação e Comunicação (educação básica e educação superior). Convertidas em sociedades anônimas, essas instituições tiveram sua razões sociais alteradas para: Anhanguera Educacional Participações S.A., Estácio Participações S.A, Kroton Educacional S.A. e Sistema Educacional Brasileiro S.A. (SEB), respectivamente. Não é por acaso que a composição societária dessas empresas foi alterada pela saída progressiva dos sócios individuais, substituídos por fundos de investimento em renda variável e por outras empresas.

É importante salientar que o mecanismo de captação de recursos por meio do mercado de capitais, seja via fundos específicos, seja via lançamento de ações em bolsa, permite a capitalização concentrada no tempo de grande aporte de recursos, de modo que subsidia o processo intenso de aquisições/fusões, visando ao crescimento em larga escala. Não é à toa que as quatro companhias têm realizado diversas aquisições nos últimos anos, ${ }^{16}$ fazendo com que seu patrimônio líquido apresente desempenho significativo: enquanto no SEB e na Estácio houve um acréscimo de $11,45 \%$ e $13 \%$, respectivamente, os grupos Kroton e Anhanguera tiveram um incremento extraordinário de $82 \%$ e 117\%, respectivamente. Em 2011, o SEB deixou de ter cotação de suas ações no mercado acionário. A Kroton, a Anhanguera e a Estácio permanecem cotadas na bolsa de valores brasileira e contam, respectivamente, com 11.297, 13.742 e 10.890 investidores, entre pessoas físicas e clubes de investimento. Outro dado importante é a participação do setor "serviços educacionais" na BM\&FBOVESPA. Entre abril de 2011 e março de 2012, este representava $0,43 \%$ das negociações e $0,53 \%$ em volume monetário. ${ }^{17}$

16 Sobre as operações efetuadas por cada delas, consultar Oliveira (2009).

17 Consulta às empresas listadas na $\mathrm{BM} \& \mathrm{FBOVESPA}$ no setor "serviços educacionais" no site: <http://www.bmfbovespa.com.br/home.aspx?idioma=pt-br >. Acesso em: abril 2012. 
Torna-se relevante analisar as implicações do surgimento desse novo modelo de empresa educacional. Em primeiro lugar, vale enfatizar que esses dois instrumentos financeiros estabelecem o comprometimento da gerência com os interesses dos acionistas/cotistas. Isso significa dizer que os objetivos da empresa transcendem a maximização do lucro, uma vez que ficam subordinados à maximização do valor acionário no mercado de capitais. Nesse sentido, todas as estratégias de gestão devem convergir para a ampliação dos lucros de curto prazo (Aguilera; Jackson, 2003; Lanzonick; O’Sullivan, 2000). Em segundo lugar, o controle sobre a origem do capital (nacional ou estrangeiro) fica comprometido, já que o capital de risco proveniente dos fundos de private equity e do investimento em renda variável (ações), ao mesmo tempo em que pulveriza a propriedade, permite a aquisição e a concentração societária por parte de especuladores ou de outras empresas educacionais estrangeiras, de modo que interfere nas decisões centrais administrativas por meio da compra de ações ordinárias que dá direito a voto nas assembleias de acionistas.

É oportuno lembrar que as novas estratégias de acumulação de capital no setor educacional, por meio do mercado de capitais, que se tornaram factíveis para um grupo ainda restrito de IES mercantis, fazem parte das transformações ocorridas no mercado financeiro mundial, a partir dos anos de 1970, de liberação e desregulamentação dos fluxos financeiros, da interligação dos mercados, da criação de inovações financeiras (derivativos, securitização, contratos futuros etc.) e de fundos de investimentos institucionais, que estudiosos denominam de processo de "financeirização". ${ }^{18} \mathrm{O}$ fenômeno tomou grandes proporções na economia americana e tornou-se bastante evidente nos países desenvolvidos. Ainda que a economia brasileira tenha sofrido sua influência, o financiamento via mercado de capitais ainda é demasiado incipiente. Entretanto, no caso específico da educação superior, há fortes indícios de "financeirização" no âmbito do comportamento das empresas educacionais, na medida em que a lógica dos negócios passou a ser a "dominação da maximização do valor ao acionista entre os objetivos corporativos" (Guttmann, 2008, p. 12). Em outras palavras, as decisões empresariais são tomadas, em última instância, visando ao aumento da proporção de lucros pagos na forma de dividendos. Com isso, os investidores institucionais têm papel central conforme utilizam o direito de propriedade para impor, como indicador de desempenho, o acréscimo nos rendimentos trimestrais por ação, e, portanto, a lógica financeira prevalece nas diretorias e na adoção das normas de governança corporativa. A prioridade são os resultados de curto prazo em detrimento das atividades de longo prazo.

18 Autores de diversas correntes teóricas investigaram a financeirização e o regime de acumulação dominado pelas finanças. No Brasil, a interpretação pioneira pertence a José Braga (2000), desenvolvida em sua tese de doutoramento em meados dos anos 1980. Para um mapeamento das abordagens do processo de financeirização e sobre o regime de crescimento conduzido pelas finanças no Brasil, consultar Miguel Bruno et al. (2009). 
Sob a feição das finanças corporativas, o crescimento da atividade ocorre por meio de fusões e aquisições, bem como pelos fundos de private equity, que são decisivos na busca pelo controle acionário dos negócios. Guttmann (2008, p. 13) alerta para os efeitos deletérios da financeirização na medida em que

[...] o preço da ação é, portanto, a variável-chave em torno da qual a gestão corporativa organiza a sua atuação, incitando reaquisições frequentes de ações, o uso de ações como moeda, o afrouxamento das normas contábeis e a manipulação de demonstrações financeiras.

A nova lógica financeira das IES mercantis acompanhada das demais estratégias organizacionais são incompatíveis com os princípios que norteiam o processo educativo. Esse modelo institucional adaptado ao segmento educacional promove conflitos evidentes entre os valores educacionais e dos negócios, à medida que os provedores corporativos, virtuais e aqueles com fins lucrativos manifestam um êthos que privilegia a grande empresa e a realização individual, e dessa forma exacerba-se uma abordagem instrumentista da educação (Ryan, 2001).

\section{CONCLUSÃO}

A classificação de particular em sentido estrito formalizou uma situação concreta vivida por grande parte das IES privadas brasileiras. O status jurídico de empresa educacional teve efeito inicial de aumento nos custos operacionais pelo pagamento de impostos ao erário público. Contudo, em meados dos anos 2000, a adesão ao PROUNI restabelece parte da desoneração fiscal. Com isso, as IES lucrativas permaneceram tendo acesso a recursos públicos indiretos e passaram a usufruir dos mercados financeiros. $\mathrm{O}$ crescimento do segmento tem sido bastante significativo, tanto na modalidade presencial como a distância.

O fenômeno recente que não pode ser ignorado é o movimento multifacetado de financeirização, oligopolização e internacionalização da educação superior brasileira. Ainda que o processo de mercantilização restrinja-se a poucas instituições de educação superior mercantis, esses estabelecimentos representam um número expressivo de matrículas e cursos. Mais do que isso, é um elemento central na análise acerca dos limites e das possibilidades da política pública educacional e mostra-se incompatível com o processo educativo. O caráter mercantil no nível superior torna-se central tanto no que tange à interferência política no processo decisório, por meio da atuação de lobbys e de bancadas no Congresso Nacional que são financiadas pelos grupos com maiores recursos econômicos, como pelas dificuldades enfrentadas pelo poder público em neutralizar o avanço do movimento de concentração e internacionalização do capital no setor, inerente às atividades econômicas mais pujantes sob o domínio do capitalismo globalizado e oligopolista.

A despeito da importância que o setor educacional lucrativo vem adquirindo no Brasil e no mundo, o que pôde ser observado no IV Fórum Acadêmico dos BRICS realizado no mês de março de 2012 - no qual uma das mesas de discussão 
chamava-se "Skilling and direct investments in education sector" -, é curioso notar que o INEP deixou de divulgar as informações discriminadas relativas às instituições lucrativas e não lucrativas no censo da educação superior de 2010, o que impossibilita a análise quantitativa sobre o segmento empresarial.

Torna-se necessário o acompanhamento e o aprofundamento dos estudos sobre o tema e a construção de uma agenda futura de pesquisas que envolva estudos comparativos sobre o segmento mercantil entre o caso brasileiro e os países latino-americanos e os países em desenvolvimento.

\section{REFERÊNCIAS}

Aguilera, Ruth; Jackson, Gregory. The cross-national diversity of corporate governance: dimensions and determinants. Academy of Management Review, New York: Academy of Management, v. 28, n. 3, p. 447-465, 2003.

Ацтвасн, Philip G. Knowledge and education as international commodities: the collapse of the common good. Current Issues in Catholic Higher Education, Washington, DC: Association of Catholic Colleges and Universities, n. 22, p. 55-60, 2002. Disponível em: <www.bc.edu/bc_org/avp/soe/cihe/newsletter/News28/text001.htm>. Acesso em: 15 jun. 2011.

Baldan, João Carlos. Concorrência em confronto. Ensino Superior, São Paulo: Segmento, n. 102, p. 36-42, mar. 2007.

Bonventti, Rodolfo Carlos. Força e transparência. Ensino Superior, São Paulo: Segmento, n. 118, jul. 2008.

Braga, José Carlos de Souza. Temporalidade da riqueza: teoria da dinâmica e financeirização do capitalismo. Campinas: Editora UNICAMP, 2000.

Brasil. Constituição da República Federativa do Brasil (1988). Brasília, 1988. Versão atualizada. Disponível em: <http://www.planalto.gov.br/ccivil_03/constituicao/ ConstituicaoCompilado.htm>. Acesso em: 5 jan. 2012.

Lei n. 9.394, de 20 de dezembro de 1996 e atualizações - Lei de Diretrizes e Bases da Educação Nacional. Brasília, 1996. Disponível em: <http://www.planalto.gov. br/ccivil_03/Leis/L9394.htm>. Acesso em: 5 jan. 2012.

Bruno, Miguel; Diawara, Hawa; Araújo, Eliane; Reis, Anna Carolina; Rubens, Mario. Finance-led growth regime no Brasil: estatuto teórico, evidências empíricas e consequências macroeconômicas. Texto para discussão IPEA, Brasília: IPEA, n. 1.455, p. 1-30, dez. 2009.

Carvalho, Cristina Helena Almeida de. O PROUNI no Governo Lula e o jogo político em torno do acesso ao ensino superior. Educação E̋ Sociedade, Campinas: CEDES, v. 27, n. 96, especial, p. 979-1.000, out. 2006.

. A politica pública para a educação superior no Brasil (1995-2008): ruptura e/ou continuidade? 2011. 465f. Tese (Doutorado em Economia) - Universidade Estadual de Campinas, Campinas, 2011. 
.; Lopreato, Francisco Luiz Cazeiro. Finanças públicas, renúncia fiscal e o PROUNI no Governo Lula. Impulso, Piracicaba: UNIMEP, v. 16, n. 40, p. 93-104, maio/ago. 2005.

CM Consultoria. Fusões e aquisiz̧ões no ensino superior: panorama setorial. 2010. Disponível em: <http://www.cmconsultoria.com.br/imagens/diretorios/diretorio4/ QuadroGeralAquisicoesIES.pdf >. Acesso em: 3 ago. 2010.

França, Luiz de. Universidades corporativas crescem $2.400 \%$ em dez anos. Veja, São Paulo: Abril, 6 maio 2009. Disponível em: <http://veja.abril.com.br/noticia/brasil/ universidades-corporativas-crescem-brasil >. Acesso em: 8 ago. 2009.

Gorgulho, Vinícius. Qualidade em pauta. Ensino Superior, São Paulo: Segmento, n. 107, p. 24-28, ago. 2007.

Guttmann, Robert. Uma introdução ao capitalismo dirigido pelas finanças. Novos Estudos, São Paulo: CEBRAP, n. 82, p. 11-33, nov. 2008.

Holanda, Juliana. O desafio é ser atraente. Ensino Superior, São Paulo: Segmento, v. 9, n. 100 , p. 28-35, 2007.

Instituto Nacional de Estudos e Pesquisas Anísio Teixeira - INEP. Censos da Educação Superior. Brasília: INEP, 1995-2010. Disponível em: <www.inep.gov.br>. Acesso em: 8 mar. 2011.

KELLY, Kathleen F. Meeting needs and making profits: the rise of for-profit degree-granting institutions. Denver: Education Commission of the States, jul. 2001.

Kinser, Kevin; Levy, Daniel C. The for-profit sector: US patterns and international echoes in higher education. Albany: University of Albany, fev. 2005. (PROPHE Working Paper Series, n. 5). Disponível em: <http://www.albany.edu/dept/eaps/prophe>. Acesso em: 3 fev. 2010.

KPMG Corporate. Pesquisa de fusões e aquisições $2012-2^{\circ}$ trimestre: espelho das transações realizadas no Brasil. 2012. Disponível em: <http://www.kpmg.com/BR/PT/ Estudos_Analises/artigosepublicacoes/Documents/Fusoes\%20e\%20Aquisicoes/2012/ FA-2otrim-2012.pdf> Acesso em: 4 out. 2012.

Lanzonick, William; O’Sullivan, Mary. Maximizing shareholder value: new ideology for corporate governance. Economy and Society, Abingdon: Taylor \& Francis Group, v. 29 , n. 1, p. 13-35, fev. 2000.

LARUCcia, Mauro Maia. Impacto da universidade corporativa nas organizações. Revista de Administração da UNIMEP, Piracicaba: UNIMEP, v. 9, n. 1, p. 146-163, jan./abr. 2011.

Morey, Ann I. The growth of for-profit higher education. Journal of Teacher Education, Washington: Sage Publications, v. 52, n. 4, p. 300-311, 2001.

Oliveira, Romualdo Pereira de. A transformação da educação em mercadoria no Brasil. Educação Ė Sociedade, Campinas: CEDES, v. 30, n. 108, p. 739-760, out. 2009. Ryan, Yoni. Higher education as a business: lessons from the Corporate World. Minerva, Netherlands: Springer, v. 39, n. 1, p. 115-135, 2001. 
Sguissardi, Valdemar. Modelo de expansão da educação superior no Brasil: predomínio privado/mercantil e desafios para a regulação e a formação universitária. Educação E Sociedade, Campinas: CEDES, v. 29, n. 105, p. 991-1.022, dez. 2008.

Silva Filho, Roberto Leal Lobo; Motejunas, Paulo Roberto; Hipólito, Oscar; Lobo, Maria Beatriz de Carvalho Melo. A evasão no ensino superior brasileiro. Cadernos de Pesquisa, São Paulo: Fundação Carlos Chagas, v. 37, n. 132, p. 641-659, set./dez. 2007. Disponível em: <http://www.scielo.br/pdf/cp/v37n132/a0737132.pdf>. Acesso em: 3 jul. 2008.

Silva Júnior, João dos Reis; Sguissardi, Valdemar. A educação superior privada no Brasil: novos traços de identidade. In: SGUISSARDI, Valdemar (Org.). Educação superior: velhos e novos desafios. São Paulo: Xamã, 2000. p. 155-177.

\section{SOBRE A AUTORA}

Cristina Helena Almeida de Carvalho é doutora em ciências econômicas pela Universidade Estadual de Campinas (UNICAMP). Professora da Universidade de Brasília (UnB).

E-mail: cristinahelenaa@yahoo.com.br 


\section{CRISTINA HELENA ALMEIDA DE CARVALHO}

\section{A mercantilização da educação superior brasileira e as estratégias de mercado das instituições lucrativas}

O artigo analisa o fenômeno recente de mercantilização da educação superior brasileira, por meio do crescimento das IES lucrativas e da adoção de estratégias de mercado na direção da financeirização, oligopolização e internacionalização. Seguindo a tendência internacional, além das táticas adotadas para atrair a demanda, houve transformações no âmbito dos negócios. Destacam-se a profissionalização da gestão e a transfiguração de universidades e centros universitários em conglomerados ou holdings. Outra estratégia consiste na venda parcial dos estabelecimentos nacionais ao capital estrangeiro, tanto por meio das aquisições realizadas por fundos private equity como pela abertura de capital das empresas educacionais na bolsa de valores (IPOs). Conclui-se que o processo de mercantilização é elemento central na análise dos limites e das possibilidades da política pública educacional, e, ao mesmo tempo, mostra-se incompatível com os princípios que norteiam o processo educativo.

Palavras-chave: educação superior; mercantilização; instituições lucrativas.

The commodification of higher education and the market strategies of for-profit institutions

The article analyzes the recent phenomenon of commodification of Brazilian bigher education, through the growth of for-profit Higher Education Institutes and the adoption of market strategies in the direction of financialization, oligopolization and internationalization. Following the international trend, in addition to the tactics adopted to attract demand, there have been changes within the business. Noteworthy are the professionalization of management and the transfiguration of universities and university centers into conglomerates or holding 
companies. Another strategy involves the partial sale of domestic institutions to foreign capital, both through acquisitions by private equity funds and through the IPO of education companies on the stock market. We conclude that the process of commodification is the central element in analyzing the limits and possibilities of public education policy and, at the same time, it is incompatible with the principles that guide the educational process.

Keywords: higher education; commodification; for-profit institutions.

\section{La mercantilización de la educación superior brasileña y las estrategias de mercado de las instituciones lucrativas}

El articulo analiza el reciente fenómeno de la mercantilización de la educación superior brasileña, mediante el crecimiento de las IES lucrativas y la adopción de estrategias de mercado en la dirección de la financialización, la oligopolización y la internacionalización. Siguiendo la tendencia internacional, además de las tácticas adoptadas para atraer a la demanda, se han producido cambios dentro de la empresa. Sobresalen la profesionalización de la gestión y la transfguración de las universidades $y$ los Centros Universitarios en conglomerados o holdings. Otra estrategia consiste en la venta parcial de las instituciones nacionales al capital extranjero, tanto a través de adquisiciones por fondos de private equity como por la apertura de capital de las empresas educativas en bolsa (IPO). Se concluye que el proceso de mercantilización es el elemento central en el análisis de los límites y posibilidades de la política pública educativa, y, al mismo tiempo se muestra incompatible con los principios que guian el proceso educativo.

Palabras clave: educación superior; mercantilización; instituciones lucrativas. 